\title{
Relationship between CETP gene polymorphisms with coronary artery disease in Polish population
}

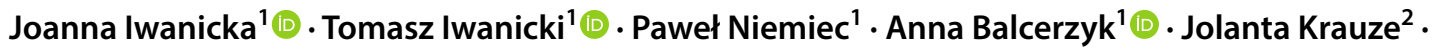 \\ Sylwia Górczyńska-Kosiorz ${ }^{3}$. Anna Ochalska-Tyka ${ }^{4}$. Władysław Grzeszczak ${ }^{3}$. Iwona Żak ${ }^{1}$
}

Received: 17 July 2018 / Accepted: 28 August 2018 / Published online: 3 September 2018

(c) The Author(s) 2018

\begin{abstract}
The cholesteryl ester transfer protein (CETP) gene encodes a hydrophobic glycoprotein that plays a crucial role in the reverse transport of cholesterol. The aim of the present study was to determine whether CETP polymorphisms (rs 1532624, rs247616 and rs708272) are associated with coronary artery disease (CAD) in a Polish population. Serum lipid levels and single nucleotide polymorphisms of CETP genes were determined in 494 subjects: 248 patients with premature CAD and 246 blood donors as controls. Selected polymorphisms were examined using TaqMan PCR analysis. We found that CAD risk was significantly higher for $\mathrm{CC}$ homozygotes and $\mathrm{C}$ allele carriers of the rs 247616 polymorphism than for carriers with the $\mathrm{T}$ allele (OR 1.89, 95\% CI 1.29-2.76, p=0.001 and OR 1.51, 95\% CI 1.14-1.99, p=0.003) and likewise for the CC genotype of the rs 1532624 polymorphism than for those with the A allele (OR 1.59, 95\% CI 1.05-2.40, $\mathrm{p}=0.026$ ). Moreover, $\mathrm{T}$ allele carriers of the rs708272 polymorphism had significantly higher total cholesterol levels compared to CC homozygotes $(\mathrm{p}<0.05)$ in the healthy controls. We also observed an allelic pattern, $\mathrm{C}_{(\mathrm{rs} 2477616)} \mathrm{C}_{(\mathrm{rs} 708272)} \mathrm{C}_{(\mathrm{rs} 1532624)}$, which increased susceptibility to $\mathrm{CAD}$ by $43 \%(\mathrm{OR}=1.43,95 \% \mathrm{CI} 1.10-1.85, \mathrm{p}=0.006)$. In conclusion, the rs 247616 and rs 1532624 polymorphisms of CETP may modulate the risk of CAD in Polish population.
\end{abstract}

Keywords CETP $\cdot$ SNPs $\cdot$ Coronary artery disease $\cdot$ Lipids $\cdot$ Linkage disequilibrium

Joanna Iwanicka

jiwanicka@sum.edu.pl

Tomasz Iwanicki

tiwanicki@sum.edu.pl

Paweł Niemiec

pniemiec@sum.edu.pl

Anna Balcerzyk

abalcerzyk@sum.edu.pl

Jolanta Krauze

jolakra@poczta.fm

Sylwia Górczyńska-Kosiorz

skosiorz@sum.edu.pl

Anna Ochalska-Tyka

a.tyka@rckik.pl

Władysław Grzeszczak

wgrzeszczak@sum.edu.pl
Iwona Żak

izak@sum.edu.pl

1 Department of Biochemistry and Medical Genetics, School of Health Sciences in Katowice, Medical University of Silesia, Medyków Street 18, 40-752 Katowice, Poland

2 1st Department of Cardiac Surgery/2nd Department of Cardiology, American Heart of Poland, S. A. Armii Krajowej Street 101, 43-316 Bielsko-Biala, Poland

3 Department of Internal Medicine, Diabetes and Nephrology, School of Medicine and Division of Dentistry in Zabrze, Medical University of Silesia, 3 Maja Street 13-15, 41-800 Zabrze, Poland

4 Regional Centre of Blood Donation and Blood Treatment in Raciborz, Sienkiewicza Street 3, 47-400 Raciborz, Poland 


\section{Introduction}

Coronary artery disease is currently one of the main causes of morbidity and mortality worldwide. Disorders of the lipid metabolism are crucial risk factors predisposing to the development of cardiovascular diseases [1].

CETP protein plays an important role in regulating cholesterol metabolism [2]. CETP is encoded by the gene CETP (16q12-21) [3], which is expressed in many tissues, including the liver, spleen, adipose tissue, small intestine, adrenal glands, kidneys, heart, and skeletal muscles [4-6]. CETP is a hydrophobic glycoprotein involved in cholesterol transport from peripheral tissues to the liver. CETP allows mutual exchange of cholesterol esters and triacylglycerols (TG) between different classes of lipoproteins [7]. Cholesterol esters are transferred from high-density lipoprotein (HDL) to low-density lipoprotein (LDL), triglyceride-rich lipoproteins (TRL) chylomicrons, and very low-density lipoprotein (VLDL), while triacylglycerols are transferred from TRL to LDL and HDL [7]. Numerous studies have shown that high gene activity may result in reduced high-density lipoprotein cholesterol (HDL-C) levels [8-11] and, consequently, the development of atherosclerotic lesions and increased risk of coronary artery disease (CAD) [12, 13]. However, not all studies confirm this dependency $[14,15]$, and combination therapy with statins and fibrates or CETP inhibitors has not produced the expected results in the reduction of cardiovascular events, despite elevated HDL-C levels [16-18]. According to some studies, there is a relationship between some polymorphic variants of CETP and CAD [19-21]. However, other authors suggest a lack of association [22-24].

Because the role of CETP polymorphisms in the context of $\mathrm{CAD}$ risk remains controversial, we decided to investigate whether three selected CETP haplotype-tagging polymorphisms (rs1532624, rs247616 and rs708272) influence the risk of the disease in the Polish population. In addition, we analyzed polymorphic variants searching for haplotype blocks and potential interactions of CETP gene alleles with traditional CAD risk factors such as smoking, hypertension, and plasma lipid disorders.

\section{Materials and methods}

\section{Subjects}

We enrolled 494 Polish Caucasians in our case-control study. All participants were inhabitants of the Upper Silesia region. The patients group included 248 individuals with angiographically confirmed premature CAD (75 females and 173 males), aged $44.62 \pm 5.95$ years. The control group consisted of 246 blood donors ( 71 females and 175 males) with negative familial history of CAD, aged $43.55 \pm 6.33$ years. CAD subjects were recruited by the same clinician from the First Department and Clinic of Cardiology at the Upper Silesian Center of Cardiology in Katowice and the First Department of Cardiac Surgery at the Upper Silesian Center of Cardiology in Katowice. Controls were selected from blood donors of the Regional Centers of Blood Donation and Blood Treatment in Katowice and Racibórz.

Inclusion and exclusion criteria, details of the medical interview, diagnosis and evaluation, criteria for CAD, myocardial infarction, and risk factors were as described previously [25]. This study was approved by the Ethics Committee of the Medical University of Silesia in Katowice (Poland) and written informed consent was obtained from all subjects.

\section{Serum lipid measurement}

Plasma total cholesterol (TC), HDL cholesterol, and triacylglycerol levels were obtained by enzymatic colorimetric methods (Analco, Warsaw, Poland). LDL cholesterol levels were calculated using the Friedewald formula [26].

\section{DNA extraction and genotyping}

Genomic DNA was extracted from peripheral leukocytes using the MasterPure genomic DNA purification kit (Epicentre Technologies, Madison, WI, USA). The CETP SNPs were analysed, namely: rs1532624 (C > A 16:56971567), rs247616 (C $>$ T 16:56955678) and rs708272 (C > T 16:56962376). The polymorphisms were genotyped using the TaqMan®Pre-designed SNP Genotyping Assay Kit (Thermo Fisher Scientific, Foster City, CA, USA). The 20- $\mu \mathrm{l}$ reaction mix consisted of: $1 \mu \mathrm{l}$ template DNA (15 ng/ $\mu \mathrm{l})$, $10 \mu \mathrm{l} \mathrm{TaqMan}{ }^{\circledR G e n o t y p i n g ~ M a s t e r ~ M i x ~(C a t . ~ \# ~ 4371355), ~}$ $1 \mu \mathrm{l}$ probe (TaqMan ${ }^{\circledR}$ Pre-designed SNP Genotyping Assay), and $8 \mu \mathrm{l}$ deionized water. The probe was diluted in TE buffer (10 mM Tris-HCl (pH 8.0), 0.1 mM EDTA) (1:1) before the reaction. PCR was performed according to the manufacturer's specifications. Genotyping was performed using a 7300 Real-Time PCR System (Applied Biosystems). Genotyping was successful in 87-98\% of participants. Genotyping accuracy was checked by re-genotyping $15 \%$ of the samples, and the reproducibility of results was $100 \%$.

\section{Statistical analysis}

Data were analysed using Statistica 12.0 (STATSOFT, Tulsa, OK, USA) and SAS 9.1 (SAS Institute Inc., NC, USA) and SNPator [27]. The Shapiro-Wilk test was used to check the normality of distribution. Comparison of 
quantitative data was performed by Mann-Whitney $\mathrm{U}$ test (non-normal distribution) or the Student's $t$ test (normal distribution). Allele frequencies were deduced from the genotype distributions. Hardy-Weinberg equilibrium testing, comparisons of genotype and allele frequencies between cases and control subjects and potential association of the polymorphisms with CAD clinical phenotypes were calculated using the $\chi^{2}$ (Chi square test). Statistical significance was accepted at $\mathrm{p}<0.05$. Odds ratios (OR with 95\% confidence intervals) were computed using univariate and multiple logistic regression analyses after adjustment for age, gender, and traditional CAD risk factors. When the number of individuals in any of the analysed subgroups was zero, risk ratio values $(95 \% \mathrm{CI})$ were used.

Due to the fact that patients with CAD were treated with statins, the association of genotypes and alleles of the studied polymorphisms with the parameters of lipid metabolism was analyzed only for the control group.

Haploview software was used to determine the haplotype blocks. This software uses the haplotype block definition developed by Gabriel et al. [28] and allows for the determination of haplotype blocks on the basis of population data and information about the locus of a given polymorphism in the gene structure. For assessing linkage disequilibrium (LD) measurements, $\mathrm{r}^{2}$ and $\mathrm{D}^{\prime}$ were used. According to the algorithm used, the $\mathrm{r}^{2}$ value should not be lower than 70\% (0.7). The CorelDraw Home \& Student X7 graphic software was used to present the haplotype blocks.

\section{Results}

\section{Characteristics of the study groups}

Table 1 shows the clinical and biochemical characteristics of CAD patients and blood donors. CAD patients had increased total cholesterol, LDL cholesterol, and triacylglycerol levels, as well as higher body mass index (BMI) values. Furthermore, CAD patients had significantly lower HDL cholesterol levels (Table 1).

\section{Analysis of the CETP polymorphisms}

Table 2 shows the genotypes and allele frequencies of the CETP polymorphisms. All genotype frequencies conformed to Hardy-Weinberg equilibrium. The frequency of the CC genotype of the rs 1532624 polymorphism was higher in the CAD group than in the control group $(\mathrm{OR}=1.59,95 \% \mathrm{CI}$ : $1.05-2.40, \mathrm{p}=0.026)$. The frequencies of the $\mathrm{CC}$ genotype and $\mathrm{C}$ allele of the rs 247616 polymorphism were higher in the CAD group than in the blood donor group (OR 1.89, 95\% CI $1.29-2.76, p=0.001$ and OR $1.51,95 \%$ CI $1.14-1.99$, $\mathrm{p}=0.003$, respectively).

In the case of the rs708272 polymorphism, there were no statistically significant differences in allele and genotype frequencies between the studied groups. However, we observed an increasing trend in the frequency of CC genotype and $\mathrm{C}$ allele in patients compared to that in the controls. These differences were on the border of statistical significance $(\mathrm{p}=0.084$ and $\mathrm{p}=0.077$, respectively).
Table 1 Clinical and biochemical characteristics of CAD patient and blood donor (BD) groups

\begin{tabular}{lllll}
\hline Characteristics & $\begin{array}{l}\mathrm{CAD} \\
n=248\end{array}$ & $\begin{array}{l}\mathrm{BD} \\
n=246\end{array}$ & $\begin{array}{l}\text { OR/RR } \\
(95 \% \mathrm{CI})\end{array}$ & $\mathrm{P}$ \\
\hline Age (years), mean $\pm \mathrm{SD}$ & $44.62 \pm 5.95$ & $43.55 \pm 6.33$ & - & $\mathrm{NS}$ \\
Male gender, $\mathrm{n}(\%)$ & $173(69.76)$ & $175(71.14)$ & $0.94(0.64-1.38)$ & $\mathrm{NS}$ \\
TC (mmol/L), mean $\pm \mathrm{SD}$ & $5.82 \pm 1.36$ & $5.09 \pm 1.22$ & - & $<10^{-6}$ \\
HDL-C (mmol/L),mean $\pm \mathrm{SD}$ & $1.13 \pm 0.37$ & $1.46 \pm 0.56$ & - & $<10^{-6}$ \\
LDL-C (mmol/L), mean $\pm \mathrm{SD}$ & $3.91 \pm 1.19$ & $2.98 \pm 1.23$ & - & $<10^{-6}$ \\
TG (mmol/L), mean $\pm \mathrm{SD}$ & $1.86 \pm 0.98$ & $1.38 \pm 0.72$ & - & $<10^{-6}$ \\
BMI \pm SD & $27.08 \pm 4.26$ & $26.17 \pm 3.87$ & - & 0.01 \\
Familial history of CAD, $\mathrm{n}(\%)$ & $174(72.80)$ & 0 & $\mathrm{RR}=4.96(3.98-6.21)$ & $<10^{-6}$ \\
Diabetes mellitus, $\mathrm{n}(\%)$ & $22(8.87)$ & 0 & $\mathrm{RR}=2.15(1.95-2.37)$ & $<10^{-6}$ \\
Hypertension, $\mathrm{n}(\%)$ & $138(55.65)$ & 0 & $\mathrm{RR}=3.51(2.97-4.15)$ & $<10^{-6}$ \\
Cigarette smoking, $\mathrm{n}(\%)$ & $146(28.87)$ & $67(27.26)$ & $3.82(2.62-5.58)$ & $<10^{-7}$ \\
\hline
\end{tabular}

$N S$ not statistically significant, $O R$ odds ratio, $S D$ standard deviation, $T C$ total cholesterol, $H D L-C$ highdensity lipoprotein cholesterol, $L D L-C$ low-density lipoprotein cholesterol, $T G$ triacylglycerol, $B M I$ body mass index

${ }^{a}$ Risk ratio values $(95 \% \mathrm{CI})$, univariate analysis 
Table 2 Genotype and allele frequencies of CETP in CAD patient and BD groups

\begin{tabular}{lcclll}
\hline Genotype/allele & CAD & BD & Inheritance model & OR (95\% CI) & P \\
\hline CETP rs 1532624 & & & & \\
CC & $77(32.49 \%)$ & $52(23.21 \%)$ & Dominant versus AC + AA & $1.59(1.05-2.40)$ & $0.026^{*}$ \\
CA & $119(50.21 \%)$ & $128(57.14 \%)$ & Additive, versus CC & $0.63(0.41-0.97)$ & $0.033^{*}$ \\
AA & $41(17.30 \%)$ & $44(19.64 \%)$ & Additive, versus CC & $0.63(0.36-1.10)$ & 0.10 \\
CC+CA & $196(82.70 \%)$ & $180(81.08 \%)$ & Recessive,versus AA & $1.17(0.73-1.87)$ & 0.52 \\
C & $273(57.59 \%)$ & $232(51.79 \%)$ & - & $1.27(0.97-1.64)$ & 0.076 \\
A & $201(42.41 \%)$ & $216(48.21 \%)$ & - & $0.79(0.61-1.03)$ & 0.076 \\
CETP rs247616 & & & & & \\
CC & $119(50.64 \%)$ & $75(35.21 \%)$ & Dominant, versus CT + TT & $1.89(1.29-2.76)$ & $0.001^{*}$ \\
CT & $94(40.00 \%)$ & $112(52.58 \%)$ & Additive, versus CC & $0.53(0.36-0.79)$ & $0.002^{*}$ \\
TT & $22(9.36 \%)$ & $26(12.21 \%)$ & Additive, versus CC & $0.53(0.28-1.01)$ & 0.05 \\
CC+CT & $213(90.64 \%)$ & $187(87.79 \%)$ & Recessive, versus TT & $1.35(0.74-2.46)$ & 0.33 \\
C & $332(70.64 \%)$ & $262(61.50 \%)$ & - & $1.51(1.14-1.99)$ & $0.003^{*}$ \\
T & $138(29.32 \%)$ & $164(38.50 \%)$ & - & $0.66(0.50-0.88)$ & $0.003^{*}$ \\
CETP rs708272 & & & & & \\
CC & $80(33.47 \%)$ & $63(26.25 \%)$ & Dominant; versus TC+TT & $1.41(0.95-2.09)$ & 0.084 \\
CT & $123(51.46 \%)$ & $131(45.58 \%)$ & Additive versus CC & $0.74(0.49-1.12)$ & 0.15 \\
TT & $36(15.06 \%)$ & $46(19.17 \%)$ & Additive versus CC & $0.61(0.26-1.07)$ & 0.08 \\
CC+CT & $203(84.94 \%)$ & $194(80.83 \%)$ & Recessive versus TT & $1.49(0.92-2.41)$ & 0.10 \\
C & $283(59.21 \%)$ & $257(53.54 \%)$ & - & $1.26(0.97-1.63)$ & 0.077 \\
T & $195(40.79 \%)$ & $223(46.46 \%)$ & - & $0.79(0.61-1.03)$ & 0.077 \\
\hline
\end{tabular}

$C A D$ coronary artery disease patient group, $B D$ blood donor group

*Differences statistically significant $(\mathrm{p}<0.05)$

\section{Association of the CETP polymorphisms with CAD clinical phenotypes}

There were no statistically significant associations between CETP genotypic variants and myocardial infarction, severe atherosclerosis (presence of multivessel coronary disease or critical occlusion $>90 \%$ ) observed during coronary angiography, left ventricular hypertrophy, and diabetes mellitus (data not shown).

\section{Association between genotypes of the CETP polymorphisms and lipid serum concentrations}

We analysed the potential interactions between respective CETP genotypes and traditional CAD risk factors (male gender, cigarette smoking, hypertension, overweight/obesity, and plasma lipid abnormalities). We did not find any significant differences of lipid levels between respective genotypes of two analysed SNPs; however, we observed that the $\mathrm{T}$ allele carriers (TT $+\mathrm{CT}$ genotypes) of the rs708272 polymorphism had higher TC concentrations than the $\mathrm{CC}$ homozygotes, $\mathrm{p}=0.002$ (Table 3 ).

\section{Haplotype analysis of the CETP polymorphisms}

Haplotype analysis according to the methods of Gabriel et al. did not show the existence of haplotype blocks between the CETP polymorphisms (Fig. 1). Despite the lack of haplotype blocks between the studied polymorphisms, we observed that co-occurrence of alleles $\mathrm{C}_{(\mathrm{rs} 2477616)}, \mathrm{C}_{(\mathrm{rs} 708272)}$ and $\mathrm{C}_{(\mathrm{rs} 1532624)}$ increased the risk of CAD by $43 \%$ (OR 1.43, 95\% CI 1.10-1.85, p=0.006). Frequency of this allelic pattern was $56 \%$ in the CAD group and $47.3 \%$ in the blood donors group. The presented results were obtained using the algorithm included in SNPator. We did not observe the impact of co-occurance of this three alleles on plasma lipid values among the healthy controls.

\section{Discussion}

In this study, we investigated three polymorphisms of CETP (rs1532624, rs247616 and rs708272) because of their functional significance (the effect of particular alleles and/or genotypes on gene activity) and because their role in the context of CAD is not fully clear. 
Table 3 Lipid profile distribution across genotypes of the CETP polymorphisms in $\mathrm{BD}$

\begin{tabular}{|c|c|c|c|c|}
\hline \multicolumn{5}{|l|}{$\mathrm{BD}$} \\
\hline Genotype & $\mathrm{TC}(\mathrm{mmol} / \mathrm{L}) \pm \mathrm{SD}$ & $\mathrm{LD}-\mathrm{C}(\mathrm{mmol} / \mathrm{L}) \pm \mathrm{SD}$ & $\begin{array}{l}\mathrm{HDL}-\mathrm{C} \\
(\mathrm{mmol} / \mathrm{L}) \pm \mathrm{SD}\end{array}$ & $\mathrm{TG}(\mathrm{mmol} / \mathrm{L}) \pm \mathrm{SD}$ \\
\hline \multicolumn{5}{|c|}{ CETP rs 1532624} \\
\hline $\mathrm{CC}$ & $4.78 \pm 1.01$ & $2.92 \pm 0.95$ & $1.40 \pm 0.55$ & $1.40 \pm 0.73$ \\
\hline CA & $5.15 \pm 1.25$ & $3.20 \pm 1.27$ & $1.46 \pm 0.57$ & $1.28 \pm 0.66$ \\
\hline AA & $5.26 \pm 1.39$ & $3.24 \pm 1.20$ & $1.37 \pm 0.52$ & $1.63 \pm 0.83$ \\
\hline \multicolumn{5}{|c|}{ CETP rs247616 } \\
\hline $\mathrm{CC}$ & $4.92 \pm 0.99$ & $3.05 \pm 0.95$ & $1.40 \pm 0.57$ & $1.39 \pm 0.77$ \\
\hline $\mathrm{CT}$ & $5.17 \pm 1.28$ & $3.16 \pm 1.30$ & $1.50 \pm 0.57$ & $1.30 \pm 0.62$ \\
\hline TT & $5.37 \pm 1.67$ & $3.33 \pm 1.44$ & $1.43 \pm 0.56$ & $1.63 \pm 0.97$ \\
\hline \multicolumn{5}{|c|}{ CETP rs708272 } \\
\hline $\mathrm{CC}$ & $4.71 \pm 0.96^{\mathrm{a}}$ & $2.90 \pm 0.91$ & $1.37 \pm 0.47$ & $1.42 \pm 0.69$ \\
\hline $\mathrm{CT}$ & $5.15 \pm 1.19$ & $3.16 \pm 1.20$ & $1.50 \pm 0.59$ & $1.33 \pm 0.72$ \\
\hline TT & $5.45 \pm 1.47$ & $3.28 \pm 1.34$ & $1.46 \pm 0.59$ & $1.49 \pm 0.76$ \\
\hline
\end{tabular}

${ }^{\mathrm{a}} \mathrm{TT}+\mathrm{CT}$ versus $\mathrm{CC}(\mathrm{p}=0.002)$

Analysis of the rs1532624 polymorphism of CETP showed a relationship between the CC homozygosity and increased risk of CAD in the studied Polish population sample. The observed result may be caused by the influence of this genetic variant on gene activity and thus the CETP protein concentration. Previous studies showed that people with the AA genotype had lower CETP activity and higher HDL lipoprotein level compared to the carriers of other genetic variants [29]. It can be assumed that the increased gene activity in $\mathrm{CC}$ homozygotes results in an increased exchange of triacylglycerols and cholesterol esters between HDL lipoproteins and apolipoprotein B-containing particles. LDL lipoproteins enriched in triacyclglycerols have a longer half-life and longer availability
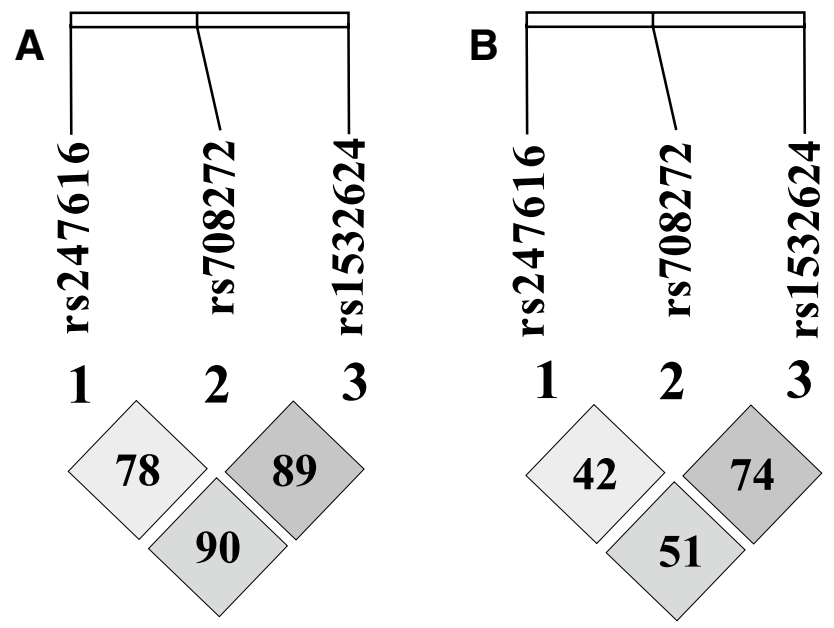

Fig. 1 Linkage disequilibrium plot of the CETP polymorphisms (A$\mathrm{D}^{\prime}$ values, $\mathrm{B}-\mathrm{r}^{2}$ values) for hepatic lipase [30], which hydrolyzing TG promotes the conversion of LDL to highly atherogenic small dense low-density lipoproteins (sd-LDL) [31]. In addition, the sd-LDL fraction is characterized by increased oxidative susceptibility and greater ability to bind to proteoglycans of the vascular wall $[32,33]$, which may intensify the atherosclerotic process and contribute to the increased risk of CAD. Since sd-LDL particles are smaller and contain less cholesterol, LDL levels may not reflect increased levels of sd-LDL [34]. This phenomenon may partially explain why we did not observe the association of the studied genotype with LDL level.

In addition, we did not observe a relationship between genotype and HDL concentration, although a previous study by Igl et al. [35] demonstrated the influence of the $\mathrm{CC}$ genotype on reduced plasma HDL levels. These differences may be due to different ethnic backgrounds of the respective patient samples, and differences in the inclusion and exclusion criteria of the specific research models. The Igl et al. cohort study took into account statins and factors such as physical activity during work and leisure, as well as diet characteristic for the lifestyle of a particular geographical area. Of course, the proposed pathomechanism and the role of the CC genotype of the rs 1532624 polymorphism are purely speculative, and would require experimental confirmation.

In the case of the rs 247616 polymorphism, we also showed that CC homozygosity increased the risk of CAD. Previous studies have indicated that the $\mathrm{T}$ allele is associated with a decrease in CETP activity and an increase in high-density lipoprotein in Caucasian and English/British populations [36, 37]. Although this polymorphism also did not affect lipid parameters in the current study, we expect 
that CC homozygosity results in increased CETP activity and consequently increased CAD risk.

Analysis of the rs708272 polymorphism did not show a statistically significant association with CAD but we observed a tendency towards a higher prevalence of $\mathrm{C}$ allele in patients than in controls. Our results for the rs 708272 polymorphism seem to be partially consistent with the results of some studies. Previous association studies have indicated that the $\mathrm{CC}$ genotype is associated with increased risk of CAD [20, 21]. In addition, Ordovas et al. found a protective role for the $\mathrm{T}$ allele in relation to $\mathrm{CAD}$ as well as a decrease in CETP activity in a subgroup of American males [38]. In context of these studies, association between allele $\mathrm{T}$ and elevated TC concentration observed in our analysis is surprising. However, it must be noted that we analyzed an effect of genotype on lipid parameters only in the group of blood donors who had no CAD symptoms and had never been treated with statins and other lipid-lowering drugs.

We note that the results obtained here should be interpreted with caution owing to the limitations of the study, resulting from a relatively small study group, which may weaken the statistical power of potential relationships between the SNPs and the plasma lipid parameters.

\section{Conclusions}

The results of the current study show that the CC genotype of the rs1532624 polymorphism as well as the $\mathrm{C}$ allele of and CC homozygosity for the rs 247616 polymorphism of CETP may be potential risk factors for CAD in the Polish population.

Acknowledgements We thank the patients for participating in the study.

Funding This research was supported by a Grants from the Medical University of Silesia in Katowice KNW-1-014/N/4/0 and KNW-1-017/N/5/0.

\section{Compliance with ethical standards}

Conflict of interest The authors declare that they have no conflict of interest.

Ethics approval This study was approved by the Ethics Committee of the Medical University of Silesia in Katowice. All procedures are compiance with ethical standards.

Informed consent Informed consent was obtained from all individual participants included in the study.
Open Access This article is distributed under the terms of the Creative Commons Attribution 4.0 International License (http://creativeco mmons.org/licenses/by/4.0/), which permits unrestricted use, distribution, and reproduction in any medium, provided you give appropriate credit to the original author(s) and the source, provide a link to the Creative Commons license, and indicate if changes were made.

\section{References}

1. Lewington S, Whitlock G, Clarke R et al (2007) Blood cholesterol and vascular mortality by age, sex, and blood pressure: a meta-analysis of individual data from 61 prospective studies with 55,000 vascular deaths. Lancet 370:1829-1839

2. Qureischie H, Heun R, Lütjohann D et al (2008) CETP polymorphisms influence cholesterol metabolism but not Alzheimer's disease risk. Brain Res 1232:1-6. https://doi.org/10.1016/j.brain res.2008.07.047

3. Agellon LB, Quinet EM, Gillette TG, Drayna DT, Brown ML, Tall A (1990) Organization of the human cholesteryl ester transfer protein gene. Biochemistry 29:1372-1376

4. Drayna D, Jarnagin AS, McLean J et al (1987) Cloning and sequencing of human cholesteryl ester transfer protein cDNA. Nature 327:632-634

5. Jiang XC, Moulin P, Quinet E et al (1991) Mammalian, adipose tissue and muscle are major sources of lipid transfer protein mRNA. J Biol Chem 266:4631-4639

6. Oliveira HC, Chouinard RA, Agellon LB et al (1996) Human cholesteryl ester transfer protein gene proximal promoter contains dietary cholesterol positive responsive elements and mediates expression in small intestine and periphery while predominant liver and spleen expression is controlled by 5 distal sequences. $\mathbf{J}$ Biol Chem 271:831-838

7. Barter PJ, Brewer HBJR, Chapman MJ, Hennekens CH, Rader DJ, Tall AR (2003) Cholesteryl ester transfer protein, a novel target for raising HDL and inhibiting atherosclerosis. Arterioscler Thromb Vasc Biol 23:160-167

8. Freeman DJ, Packard CJ, Shepherd J, Gaffney D (1990) Polymorphisms in the gene coding for cholesterol ester transfer protein are related to plasma high-density lipoprotein cholesterol and transfer protein activity. Clin Sci 79:575-581

9. Kuivenhoven JA, de Knijff P, Boer JM et al (1997) Heterozygosity at the CETP gene locus. Influence on plasma CETP concentrations and HDL cholesterol levels. Arterioscler Thromb Vasc Biol 17:560-568

10. Kark JD, Sinnreich R, Leitersdorf E, Friedlander Y, Shpitzen S, Luc G (2000) Taq1B CETP polymorphism, plasma CETP, lipoproteins, apolipoproteins and sex diff erences in a Jewish population sample characterized by low HDL-cholesterol. Atherosclerosis 151:509-518

11. Agellon LB, Walsh A, Hayek T et al (1991) Reduced high density lipoprotein cholesterol in human cholesteryl ester transfer protein transgenic mice. J Biol Chem 97:2917-2993

12. Gordon DJ, Probstfield JL, Garrison RJ et al (1989) High-density lipoprotein cholesterol and cardiovascular disease. Four prospective American studies. Circulation 79:8-15

13. Mahdy Ali K, Wonnerth A, Huber K, Wojta J (2012) Cardiovascular disease risk reduction by raising HDL cholesterol—current therapies and future opportunities. Br J Pharmacol 167:11771194. https://doi.org/10.1111/j.1476-5381.2012.02081.x

14. Vasan RS, Pencina MJ, Robins SJ et al (2009) Association of circulating cholesteryl ester transfer protein activity with incidence of cardiovascular disease in the community. Circulation 120:2414-2420. https://doi.org/10.1161/CIRCULATIO NAHA.109.872705 
15. van Acker BA, Botma GJ, Zwinderman AH et al (2008) High HDL cholesterol does not protect against coronary artery disease when associated with combined cholesteryl ester transfer protein and hepatic lipase gene variants. Atherosclerosis 200:161-167. https://doi.org/10.1016/j.atherosclerosis.2007.11.019

16. Ginsberg HN, Elam MB, Lovato LC et al (2010) Effects of combination lipid therapy in type 2 diabetes mellitus. N Engl J Med 362:1563-1574. https://doi.org/10.1056/NEJMoa1001282

17. Barter PJ, Caulfield M, Eriksson M et al (2007) Effects of torcetrapib in patients at high risk for coronary events. N Engl J Med 357:2109-2122

18. Schwartz GG, Olsson AG, Abt M et al (2012) Effects of dalcetrapib in patients with a recent acute coronary syndrome. N Engl J Med 367:2089-2099. https://doi.org/10.1056/NEJMoa1206 797

19. Cyrus C, Vatte C, Al-Nafie A et al (2016) The impact of common polymorphisms in CETP and ABCA1 genes with the risk of coronary artery disease in Saudi Arabians. Hum Genom 10:8. https://doi.org/10.1186/s40246-016-0065-3

20. Yu Q, Liu EQ, Zhao SH et al (2012) Association between TaqIB polymorphism of cholesteryl ester transfer protein and coronary artery disease in the Chinese population. J Zhejiang Univ Sci B 13:342-347. https://doi.org/10.1631/jzus.B1100264

21. Abd El-Aziz TA, Mohamed RH, Hagrass HA (2014) Increased risk of premature coronary artery disease in Egyptians with ABCA1 (R219K), CETP (TaqIB), and LCAT (4886C/T) genes polymorphism. J Clin Lipidol 8:381-389. https://doi. org/10.1016/j.jacl.2014.06.001

22. Shahid SU, Shabana NA, Cooper JA, Rehman A, Humphries SE (2017) Common variants in the genes of triglyceride and HDL-C metabolism lack association with coronary artery disease in the Pakistani subjects. Lipids Health Dis 16:24. https:// doi.org/10.1186/s12944-017-0419-4

23. Wang J, Wang LJ, Zhong Y et al (2013) CETP gene polymorphisms and risk of coronary atherosclerosis in a Chinese population. Lipids Health. https://doi.org/10.1186/1476-511X-12-176

24. Whiting BM, Anderson JL, Muhlestein JB et al (2005) Candidate gene susceptibility variants predict intermediate end points but not angiographic coronary artery disease. Am Heart J 150:243-250

25. Niemiec P, Zak I, Wita K (2007) The 242 T variant of the CYBA gene polymorphism increases the risk of coronary artery disease associated with cigarette smoking and hypercholesterolemia. Coron Artery Dis 18:339-346

26. Friedewald WT, Levy RI, Fredrickson DS (1972) Estimation of the concentration of low-density lipoprotein cholesterol in plasma, without use of the preparative ultracentrifuge. Clin Chem 18:499-502
27. Morcillo-Suarez C, Alegre J, Sangros R et al (2008) SNP analysis to results (SNPator): a web-based environment oriented to statistical genomics analyses upon SNP data. Bioinformatics 24:16431644. https://doi.org/10.1093/bioinformatics/btn241

28. Gabriel SB, Schaffner SF, Nguyen H, Moore JM, Roy J, Blumenstiel B et al (2002) The structure of haplotype blocks in the human genome. Science 296:2225-2229

29. Yehya A, Irshaid Y, Saleh AA (2013) Cholesteryl ester transfer protein rs 1532624 gene polymorphism is associated with reduced response to statin therapy. Curr Mol Pharmacol 6:156-162

30. Packard CJ (2003) Triacylglycerol-rich lipoproteins and the generation of small, dense low-density lipoprotein. Biochem Soc Trans 31:1066-1069

31. Zambon A, Bertocco S, Vitturi N, Polentarutti V, Vianello D, Crepaldi G (2003) Relevance of hepatic lipase to the metabolism of triacylglycerol-rich lipoproteins. Biochem Soc Trans 31:1070-1074

32. Berneis KK, Krauss RM (2002) Metabolic origins and clinical significance of LDL heterogeneity. J Lipid Res 43:1363-1379

33. Anber V, Griffin BA, McConnell M, Packard CJ, Shepherd J (1996) Influence of plasma lipid and LDL-subfraction profile on the interaction between low density lipoprotein with human arterial wall proteoglycans. Atherosclerosis 124:261-267

34. Hoogeveen RC, Gaubatz JW, Sun W et al (2014) Small dense low-density lipoprotein-cholesterol concentrations predict risk for coronary heart disease: the Atherosclerosis Risk In Communities (ARIC) study. Arterioscler Thromb Vasc Biol 34:1069-1077. https://doi.org/10.1161/ATVBAHA.114.303284

35. Igl W, Johansson A, Wilson JF et al (2010) Modeling of environmental effects in genome-wide association studies identifies SLC2A2 and HP as novel loci influencing serum cholesterol levels. PLoS Genet 6:e1000798. https://doi.org/10.1371/journ al.pgen. 1000798

36. Suhy A, Hartmann K, Papp AC, Wang D, Sadee W (2015) Regulation of cholesteryl ester transfer protein expression by upstream polymorphisms: reduced expression associated with rs 247616 . Pharmacogenet Genom 25:394-401. https://doi.org/10.1097/ FPC.0000000000000151

37. Papp AC, Pinsonneault JK, Wang D et al (2012) Cholesteryl ester transfer protein (CETP) polymorphisms affect mRNA splicing, HDL levels, and sex-dependent cardiovascular risk. PLoS ONE 7:e31930. https://doi.org/10.1371/journal.pone.0031930

38. Ordovas JM, Cupples LA, Corella D et al (2000) Association of cholesteryl ester transfer protein-TaqIB polymorphism with variations in lipoprotein subclasses and coronary heart disease risk: the Framingham study. Arterioscler Thromb Vasc Biol 20:1323-1329 